\title{
ARTICLE OPEN \\ Alterations in adaptive immunity persist during long-duration spaceflight
}

\author{
Brian Crucian ${ }^{1}$, Raymond P Stowe ${ }^{2}$, Satish Mehta ${ }^{3}$, Heather Quiriarte ${ }^{4}$, Duane Pierson ${ }^{1}$ and Clarence Sams ${ }^{5}$
}

BACKGROUND: It is currently unknown whether immune system alterations persist during long-duration spaceflight. In this study various adaptive immune parameters were assessed in astronauts at three intervals during 6-month spaceflight on board the International Space Station (ISS).

AIMS: To assess phenotypic and functional immune system alterations in astronauts participating in 6-month orbital spaceflight. METHODS: Blood was collected before, during, and after flight from 23 astronauts participating in 6-month ISS expeditions. In-flight samples were returned to Earth within $48 \mathrm{~h}$ of collection for immediate analysis. Assays included peripheral leukocyte distribution, T-cell function, virus-specific immunity, and mitogen-stimulated cytokine production profiles.

RESULTS: Redistribution of leukocyte subsets occurred during flight, including an elevated white blood cell (WBC) count and alterations in $\mathrm{CD}^{+}{ }^{+} \mathrm{T}$-cell maturation. A reduction in general $\mathrm{T}$-cell function (both $\mathrm{CD} 4^{+}$and $\mathrm{CD} 8^{+}$) persisted for the duration of the 6-month spaceflights, with differential responses between mitogens suggesting an activation threshold shift. The percentage of $\mathrm{CD}^{+} \mathrm{T}$ cells capable of producing IL-2 was depressed after landing. Significant reductions in mitogen-stimulated production of IFNy, IL-10, IL-5, TNFa, and IL-6 persisted during spaceflight. Following lipopolysaccharide (LPS) stimulation, production of IL-10 was reduced, whereas IL-8 production was increased during flight.

CONCLUSIONS: The data indicated that immune alterations persist during long-duration spaceflight. This phenomenon, in the absence of appropriate countermeasures, has the potential to increase specific clinical risks for crewmembers during exploration-class deep space missions.

npj Microgravity (2015) 1, 15013; doi:10.1038/npjmgrav.2015.13; published online 3 September 2015

\section{INTRODUCTION}

Immune system alterations have been previously characterized as essentially a postflight phenomenon, in animal studies or using terrestrial modeled microgravity or in-flight cell culture. It generally consists of altered cytokine production patterns, ${ }^{1-5}$ natural killer (NK)-cell function, ${ }^{6-9}$ leukocyte distribution, ${ }^{10,11}$ monocyte function, ${ }^{12}$ granulocyte function, ${ }^{11,13}$ T-cell intracellular signaling, $^{14-16}$ neuroendocrine responses, ${ }^{17,18}$ and leukocyte proliferation following activation. ${ }^{19,20}$ The capability of lymphocytes to migrate through tissues was inhibited in modeled microgravity conditions. ${ }^{21}$ Little in-flight information has been generated regarding immunocompetence of astronauts during spaceflight. Taylor et al. found that delayed-type hypersensitivity reactions to recall antigens were blunted during short-duration spaceflight. ${ }^{22}$ Recently, immune alterations were characterized in astronaut subjects participating in short-duration Space Shuttle missions, ${ }^{23}$ confirming the presence of an in-flight phenomenon, as opposed to merely a stress-response related to landing and readaptation. The reactivation of latent herpesviruses, including Epstein-Barr virus (EBV), cytomegalovirus (CMV), and varicella zoster virus (VZV), has been well documented in astronauts participating in short-duration spaceflight. ${ }^{24-28}$ The reactivation of latent herpesviruses in astronauts was recently found to correlate with altered immunity. ${ }^{29}$ It remains unknown, however, whether the phenomenon observed during short-duration flights would persist during long-duration spaceflight or resolve, having merely been owing to the stressors of launch and early adaptation to spaceflight. A paucity of data exists regarding human immunity during long-duration spaceflight. In a very limited number of subjects, it was reported that cell-mediated immunity was depressed during flights on board the Russian Mir Space Station. ${ }^{30}$ Should immune alterations persist for the duration of a human Mars mission, it could elevate specific clinical risks to crewmembers including infectious disease, allergies and hypersensitivities, autoimmunity, altered wound healing, and the consequences of persistent latent herpes virus reactivation. Certainly in synergy with increased radiation exposure, there would be an increased concern for the development of malignancy. The final construction of the International Space Station (ISS), with its unique laboratory support facilities and sixperson crew, afforded an excellent opportunity to perform a comprehensive assessment of immune parameters as they equilibrate during long-duration spaceflight. In this study we performed an integrated assessment of immune function, cytokine profiles, and viral immunity during flight on board the ISS. Blood samples were collected at three intervals during flight, always shortly before undock of a visiting vehicle, and were immediately returned (ambient) for analysis. This analysis strategy was preferred, since as laboratory analysis capability on board ISS is currently limited, terrestrial analysis of samples collected on-orbit afforded a wider array of analytical capability. As microgravity cell culture has been found to inhibit T-cell activation, terrestrial

\footnotetext{
${ }^{1}$ Biomedical Research and Environmental Sciences Division, NASA Johnson Space Center, Houston, TX, USA; ${ }^{2}$ Microgen Laboratories, La Marque, TX, USA; ${ }^{3}$ Biomedical Research and Environmental Sciences Division, Enterprise Advisory Services, Inc., Houston, TX, USA; ${ }^{4}$ Biomedical Research and Environmental Sciences Division, JES Tech, Houston, TX, USA and ${ }^{5}$ Space and Clinical Operations Division, Houston, TX, USA.

Correspondence: B Crucian (brian.crucian-1@nasa.gov)
}

Received 28 January 2015; revised 26 June 2015; accepted 13 July 2015 
$4{ }^{\circ} \mathrm{C}$. Following incubation, the supernatants were removed and the cells were fixed in $4.0 \%$ paraformaldehyde for $10 \mathrm{~min}$. To detect intracellular production of IFNY or IL-2 (following surface marker staining), the fixed PBMCs were resuspended in $200 \mu \mathrm{l}$ of permeabilization buffer $(5.0 \%$ nonfat dry milk and $0.5 \%$ saponin in phosphate-buffered saline (PBS)) to which $0.5 \mu \mathrm{g}$ of labeled mouse antibody to human IL-2 (FITC), IFNY (PE), CD8 $(E C D)$, and $C D 3$ (PC5) was added. Fluorescent-labeled antibodies were obtained from Beckman-Coulter (Miami, FL, USA). The cells were incubated at $4^{\circ} \mathrm{C}$ for $16 \mathrm{~h}$ and then washed in PBS-containing saponin. The cells were then resuspended in $1.0 \%$ paraformaldehyde and analyzed on a Beckman Coulter XL flow cytometer. The gating strategy consisted of T-cell identification, resolution of CD4 and CD8 subsets, followed by resolution and enumeration of cells producing IFNY and IL-2.

\section{Secreted cytokine cytometric bead array}

For analysis of secreted Th1/Th2 cytokine profiles, $1 \times 10^{6}$ PBMCs were cultured in $1.0 \mathrm{ml} \mathrm{RPMI}$ media. Mitogenic stimulation consisted of culture in the presence of $0.125 \mu \mathrm{g} / \mathrm{ml}$ anti-CD3 and $0.25 \mu \mathrm{g} / \mathrm{ml}$ anti-CD28 (both from Becton Dickinson) to activate T cells only via the T-cell receptor (TCR), $10 \mathrm{ng} / \mathrm{ml} \mathrm{PMA}+2 \mu \mathrm{g} / \mathrm{ml}$ ionomycin (both Sigma-Aldrich) as a broader pharmacologic stimulus, or $10 \mu \mathrm{g} / \mathrm{ml}$ lipopolysaccharide (LPS) Escherichia coli serotype 026:B6 (Sigma-Aldrich) for monocyte activation. Cultures were incubated for $48 \mathrm{~h}$. Supernatants were then removed and frozen until analysis. On CD3/CD28 and PMA-I cultures, a Th1/Th2 cytometric bead array assessment was performed according to the manufacturer's instructions (Becton Dickinson). This array simultaneously analyzes secreted IL-17A, IFNY, TNFa, IL-10, IL-5, IL-4 and IL-2 using distinct bead populations that fluoresce to varying degrees along a single emission wavelength. For LPS-stimulated cultures, an inflammatory cytometric bead array (CBA) assay was performed, which assessed secreted TNFa, IL-10, IL-6, $\mathrm{IL}-1 \beta$ and IL-8. For analysis, a Beckman-Coulter flow cytometer was configured to resolve all six-bead populations and allow increases in cytokine concentration to be detected. Both CBA assay kits were obtained from Becton Dickinson. As all crewmember samples were batch-analyzed, data were recorded as mean fluorescence intensity (MFI) and converted to $\mathrm{pg} / \mathrm{ml}$ concentration to show subject-relative cytokine production alterations throughout the mission. For this assay, the MFIs directly relate to supernatant concentration of each cytokine. Conversion was performed by plotting subject MFI data against the MFI data derived for the standard curve. The lone exception is IFNy, for which the MFI data are presented. For this cytokine only, a defective standard reagent precluded the conversion of MFI data to concentration.

\section{Tetramer assay}

HLA-A*0201-restricted tetramers (EBV BMLF; CMV pp65) were obtained from Beckman Coulter (San Diego, CA). PBMCs were incubated with PElabeled viral-peptide-specific tetramer complexes that bind to the major histocompatibility molecule (MHC), along with CD8-PerCP (BD Biosciences), in Dulbecco's phosphate-buffered saline (dPBS) with $2 \%$ fetal calf serum for $30 \mathrm{~min}$ at room temperature. Cells were then washed and fixed in 1\% paraformaldehyde and analyzed on a FACSCalibur flow cytometer using CellQuest software for data collection and analysis.

\section{Peptide stimulation}

Intracellular cytokine staining assays were performed as previously described. ${ }^{33}$ PBMCs were isolated from heparinized whole blood by density-gradient centrifugation and washed three times in dPBS prior to use in functional studies. PBMCs were used immediately and stimulated with HLA-A*0201-restricted epitopic peptides $(10 \mu \mathrm{g} / \mathrm{ml} /$ peptide) or controls (PBS). Peptides used in this study were CMV pp65 (residues 495-503; NLVPMVATV) and EBV BMLF (residues 280-288; GLCTLVAML). Costimulatory monoclonal antibodies (mAbs) - CD28 and CD49d mAbs $(1 \mu \mathrm{g} / \mathrm{ml}$ each) (BD Immunocytometry Systems, San Jose, CA, USA)-were added to each tube. The tubes were vortexed and incubated for $6 \mathrm{~h}$ at $37^{\circ} \mathrm{C}$ with $5 \% \mathrm{CO}_{2}$, with the addition of brefeldin A $(10 \mu \mathrm{g} / \mathrm{ml}$; Sigma, St. Louis, MO, USA) for the last $5 \mathrm{~h}$. Following stimulation, cells were washed in PBS, incubated for 5 min at $37^{\circ} \mathrm{C}$ in $0.02 \%$ EDTA and washed in dPBS. Cells were then sequentially incubated for $10 \mathrm{~min}$ in FACSLyse and FACSPerm solutions (both from Becton-Dickinson Biosciences), washed, and stained with anti-IFNy (PE), anti-CD8 (PerCP), and anti-CD69 (APC) antibodies. Samples were then fixed in $1 \%$ paraformaldehyde and analyzed by four-color flow cytometry using a FACSCalibur cytometer and CellQuest software (both BD Biosciences). Flow cytometry data were analyzed and presented using Flow Jo software (Tree Star, San Carlos, CA, USA); 25,000 events were analyzed for each sample.

\section{Statistical analysis}

This was a longitudinal study of human subjects participating in spaceflight. The L-180 sample was considered the best baseline, as samples collected closer to launch may be influenced by premission stress. Statistical significance for each assay was evaluated using Student's paired $t$-test. For each assay, the data were first confirmed as a normal distribution using the Shapiro-Wilk Normality Test. Significance was then determined by comparing the mean value for the baseline L-180 timepoint to all in-flight and postlanding values. The mean differences between time points were considered significant if $P<0.05$ and are indicated as such $\left(^{*}\right)$ on each data figure. Where normality failed, data were examined for outlier values, and significance was reanalyzed with outlier values removed. In only one instance, indicated in the text, this altered significance for an individual timepoint.

\section{RESULTS}

Peripheral leukocyte distribution

Among the bulk leukocyte subsets (WBC, differential, lymphocyte subsets), significant differences were observed during spaceflight. Relative to L-180 baseline data, both the absolute WBC and granulocyte levels increased during flight, whereas levels of lymphocytes and monocytes were unaltered during flight (Figure 1a). Levels of T cells, CD4 and CD8 subsets, and memory $\left(\mathrm{CD} 45 \mathrm{RO}^{+}\right) \mathrm{T}$ cells were also unaltered during spaceflight (Figure $1 \mathrm{~b}$, c). The level of NK cells was elevated at the late in-flight timepoint only, whereas B-cell levels were unaltered during flight (Figure 1b). In-flight alterations were observed among specific subsets of $C D 8^{+}$ T cells. The absolute level of active cytotoxic $\left(\mathrm{CD} 28^{+} / \mathrm{CD} 244^{+}\right) \mathrm{CD} 8^{+}$ $T$ cells was significantly increased only at the early in-flight time point, whereas the corresponding late senescent $\left(\mathrm{CD} 28^{-} / \mathrm{CD} 244^{+}\right)$ T-cell population were significantly decreased during flight at the mid-mission timepoint (Figure 1d). For both subsets, nonsignificant in-flight data time points had mean data trending in a similar manner, and the mean levels of undifferentiated (true naive) $C D 8^{+}$ T cells $\left(\mathrm{CD} 28^{+} / \mathrm{CD} 244^{-}\right)$trended downward through all in-flight data time points (Figure 1d). Central memory-effector T-cell subsets were also evaluated; however, because of large standard errors, significant in-flight differences were observed only for the central memory subset of cells $\left(\mathrm{CD} \mathrm{L}^{-} / \mathrm{CD} 45 \mathrm{RA}^{+}\right)$, which decreased early in-flight but trended similarly throughout flight (Figure 1e). Levels of early senescent $\left(\mathrm{CD}_{57}{ }^{+}\right)$T-cell subsets (both $\mathrm{CD}^{+}$and $\mathrm{CD}^{+}$) trended negatively during flight; however, the decrease reached significance for only the $\mathrm{CD} 4^{+} / \mathrm{CD} 57^{+}$subset immediately after landing (Figure 1f). Interestingly, among constitutively activated T-cell subsets disparity was observed between early-activated $\left(\mathrm{CD} 69^{+}\right)$ and late-activated (HLA-DR ${ }^{+}$) subsets. For both $\mathrm{CD} 4$ and CD8 ${ }^{+}$T-cell subsets, early-activated $T$ cells trended to be elevated, but reached significance only at $\mathrm{R}+0$ for the $\mathrm{CD}^{+}$subset (Figure $1 \mathrm{~g}$ ). In contrast, levels of late-activated $\mathrm{T}$ cells (both subsets) trended downward from baseline during flight, reaching significance for the CD8 population at the mid-mission timepoint and for the CD4 population at $\mathrm{R}+0$ (Figure 1h). Levels of $\mathrm{T}$ cells specific for viral peptides from EBV and CMV were unaltered during flight (Figure 1i).

\section{Intracellular cytokine profiles}

After $6 \mathrm{~h}$ of stimulation in the presence of PMA+ionomycin and monensin as described, the percentage of T-cell subsets capable of being stimulated to produce cytokine was assessed. The percentage of $\mathrm{CD}^{+} \mathrm{T}$ cells capable of being stimulated to produce IFN $\gamma$ was unchanged during spaceflight (Figure 2). The percentage of $\mathrm{CD}^{+} \mathrm{T}$ cells capable of being stimulated to produce IL-2 was also unchanged during spaceflight, but it was significantly reduced immediately after landing (Figure 2). 
a

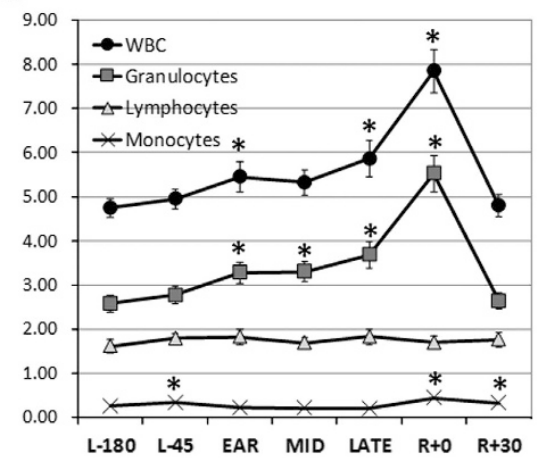

d

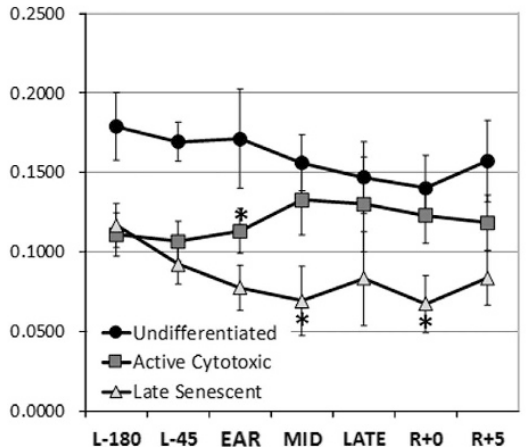

g

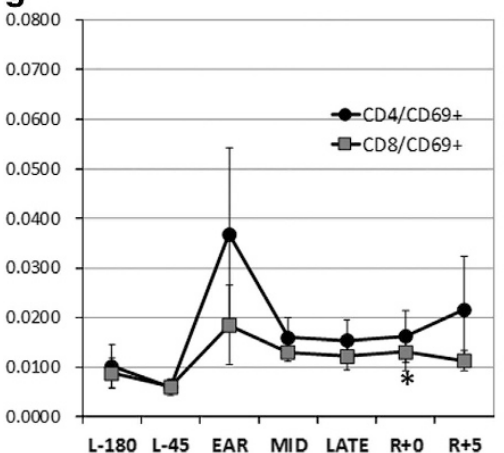

b

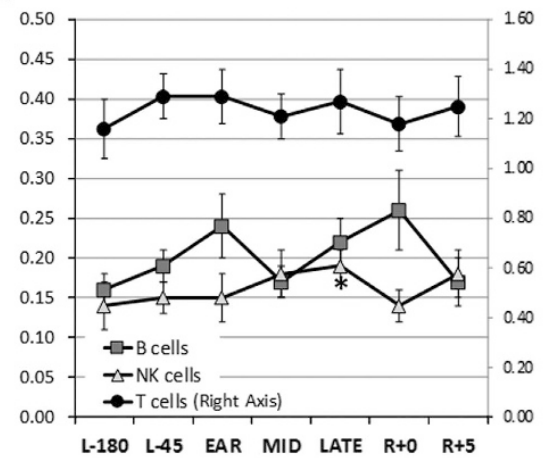

e

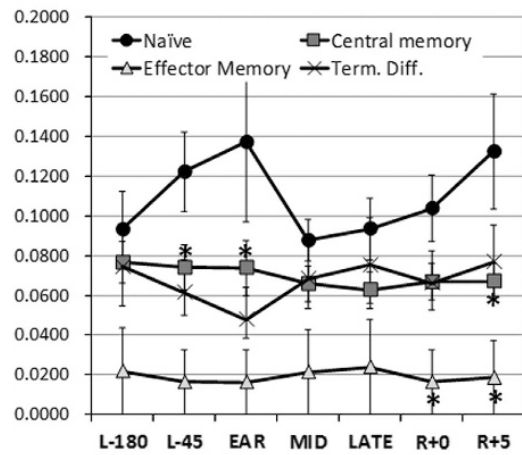

h

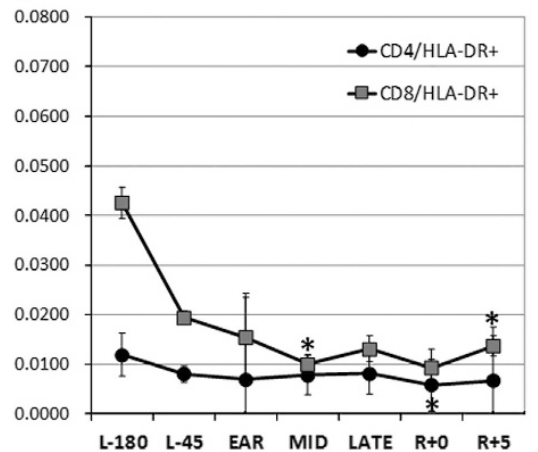

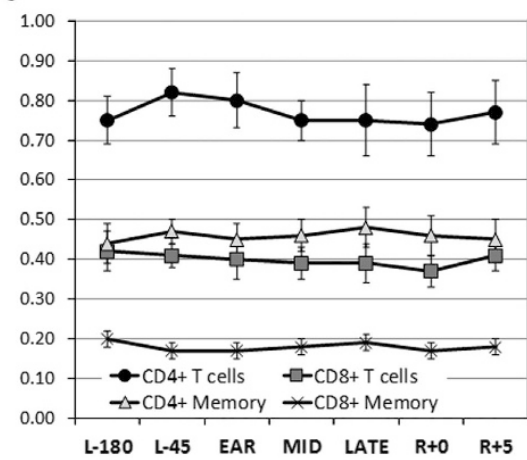

f

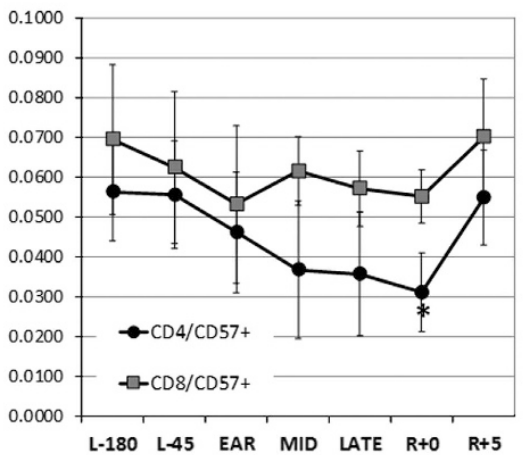

i

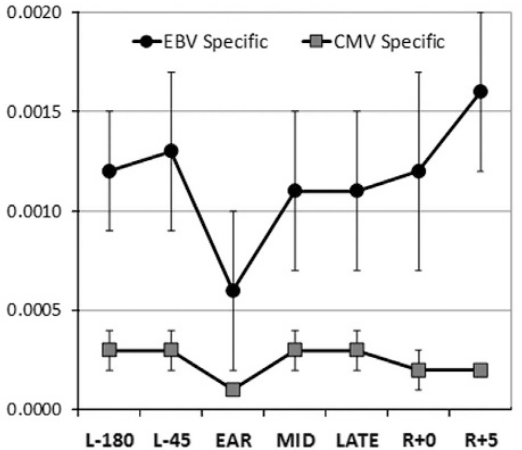

Figure 1. Absolute peripheral blood levels $(\times 1000 \mathrm{cell} / \mu \mathrm{l})$ for the indicated leukocyte, lymphocyte, and T-cell subpopulations before, during (early, mid-mission, and late) and following spaceflight. (a) Leukocyte subsets; (b) lymphocyte subsets; (c) T cell subsets; (d) cytotoxic CD8 ${ }^{+}$ T cell subsets; (e) central memory $\mathrm{CD}^{+} \mathrm{T}$ cell subsets; (f) senescent $\mathrm{T}$ cell subsets; $(\mathbf{g}$ and $\mathbf{h})$ constitutively activated $\mathrm{T}$ cell subsets; (i) viral peptide-specific T cell subsets. Data are presented as mean \pm s.e. Significance was evaluated via a Student's Paired $t$-test, by comparing all other data points to L-180 baseline data. Significant differences $(P \leqslant 0.05)$ are indicated $\left(^{*}\right)$. Sample size for all data is 23 astronaut subjects, except for EBV- and CMV-specific T cells, where the assay is restricted to HLA-A2-positive subjects $(n=8)$. CMV, cytomegalovirus; EBV, Epstein-Barr virus.

\section{Early T-cell function}

After $24 \mathrm{~h}$ of T-cell stimulation in the presence of SEA+SEB, the percentage of $\mathrm{CD} 9^{+}$and $\mathrm{CD} 69^{+} / \mathrm{CD} 25^{+}$cells decreased during flight for both $\mathrm{CD}^{+}$and $\mathrm{CD} 8^{+} \mathrm{T}$-cell subsets (Figure 3a). All four parameters were significantly decreased at the early timepoint. Although there seemed to be a general trend towards recovery through the mid-mission and late in-flight time points, all values remained significantly depressed except for the $\mathrm{CD}^{+}$subset, which recovered function by the late timepoint (Figure 3a). When T cells were stimulated directly using antibodies to CD3 and CD28, no in-flight alteration was observed among either early-activated subset $\left(\mathrm{CD} 69^{+}\right)$, but the $\mathrm{CD}^{+}$subset reflecting full activation $\left(\mathrm{CD} 69^{+} / \mathrm{CD} 25^{+}\right)$was significantly decreased at the early timepoint only (Figure $3 b$ ).
Virus-specific T-cell function

Function of both EBV- - and CMV-specific T cells was determined by peptide stimulation followed by intracellular determination of IFNy. For both subsets, quantity was determined by the MHCtetramer method. The functional percentage of both EBV and CMV peptide-specific $T$ cells was calculated as described above. The absolute levels of both EBV and CMV peptide-specific T cells were not significantly altered at any phase of flight, nor post flight (Figure 4).

\section{Mitogen-stimulated cytokine profiles}

Secreted cytokine profiles were determined in culture supernatants following mitogen stimulation for $48 \mathrm{~h}$. After T-cell-specific stimulation (anti-CD3 and anti-CD28 antibodies), production of 


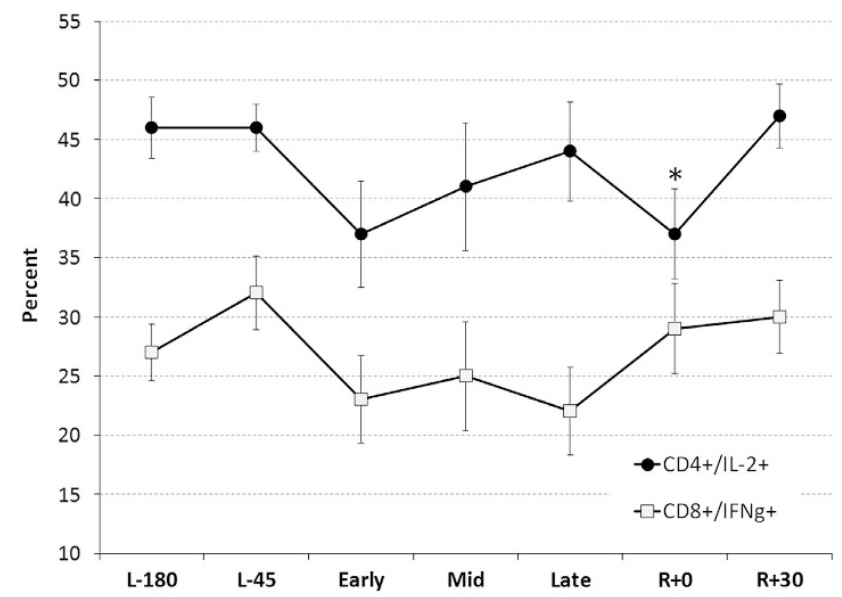

Figure 2. Intracellular cytokine analysis; mean percentage of T cells in samples collected before, during (early, mid-mission, and late) and after spaceflight that were capable of being stimulated to produce either IL-2 $\left(\mathrm{CD}^{+}\right)$or IFN $\gamma\left(\mathrm{CD}^{+}\right)$following mitogenic stimulation Purified peripheral mononuclear cells were stimulated with PMA +ionomycin for $4 \mathrm{~h}$; data are expressed as percentage of $\mathrm{T}$ cells that were positive. Data are presented as mean \pm s.e. Significance was evaluated via a Student's paired $t$-test by comparing all other data points to $L-180$ baseline data. Significant differences $(P \leqslant 0.05)$ are indicated $\left(^{*}\right)$. Sample size for all data is 23 ISS astronaut subjects.

IFNy, IL-4, IL-5, IL-10, and IL-17A were all significantly reduced during flight at all three in-flight time points (Figure 5a). Following culture in the presence of PMA and ionomycin, a stronger mitogenic stimulus which bypasses some early intracellular signaling events and may activate most leukocyte populations, production of IFN $\gamma$, IL-4, IL-5, IL-10, IL-17A, TNFa, and IL-6 was significantly decreased at all three in-flight time points (Figure $5 b$ ). Following stimulation with LPS, production of both IL-1b and IL-10 was depressed at least one time point during flight, whereas production of IL-8 was actually elevated during flight at the early and mid-mission time points (Figure $5 \mathrm{c}$ ).

\section{DISCUSSION}

Investigations of immunity immediately after spaceflight may be confounded by the high-G reentry and stressors of readaptation to terrestrial gravity following prolonged deconditioning. Some studies have indicated that the function of various immune subpopulations may be depressed either following or during short-duration spaceflight. ${ }^{2,10-13,18,19,23}$ Immune studies associated with short-duration spaceflight, typically the $\sim 7$ - to 14-day durations of a Space Shuttle mission, are essentially conducted during what is perceived to be the 'early adaptation' phase of spaceflight. Space Shuttle missions are typically extremely busy and stressful, more so than a typical work day on board ISS, where crew schedules are managed relative to the longer mission duration. Because of these conditions, short-duration data may not reflect how immunity may function during long-duration spaceflight. With limited exceptions, the status of the human immune system during long-duration spaceflight has remained uncharacterized. On board, the Russia Mir space station, the 'Multitest' assay of cell-mediated immunity was performed on three long-duration subjects, and the data indicated that cell-mediated immunity was depressed during spaceflight. ${ }^{30}$ Otherwise, no comprehensive immune investigation has been conducted on human subjects during long-duration spaceflight.

The advent of ISS has afforded researchers an excellent opportunity to address our persisting knowledge gaps related to human physiology during space travel. In the study reported here
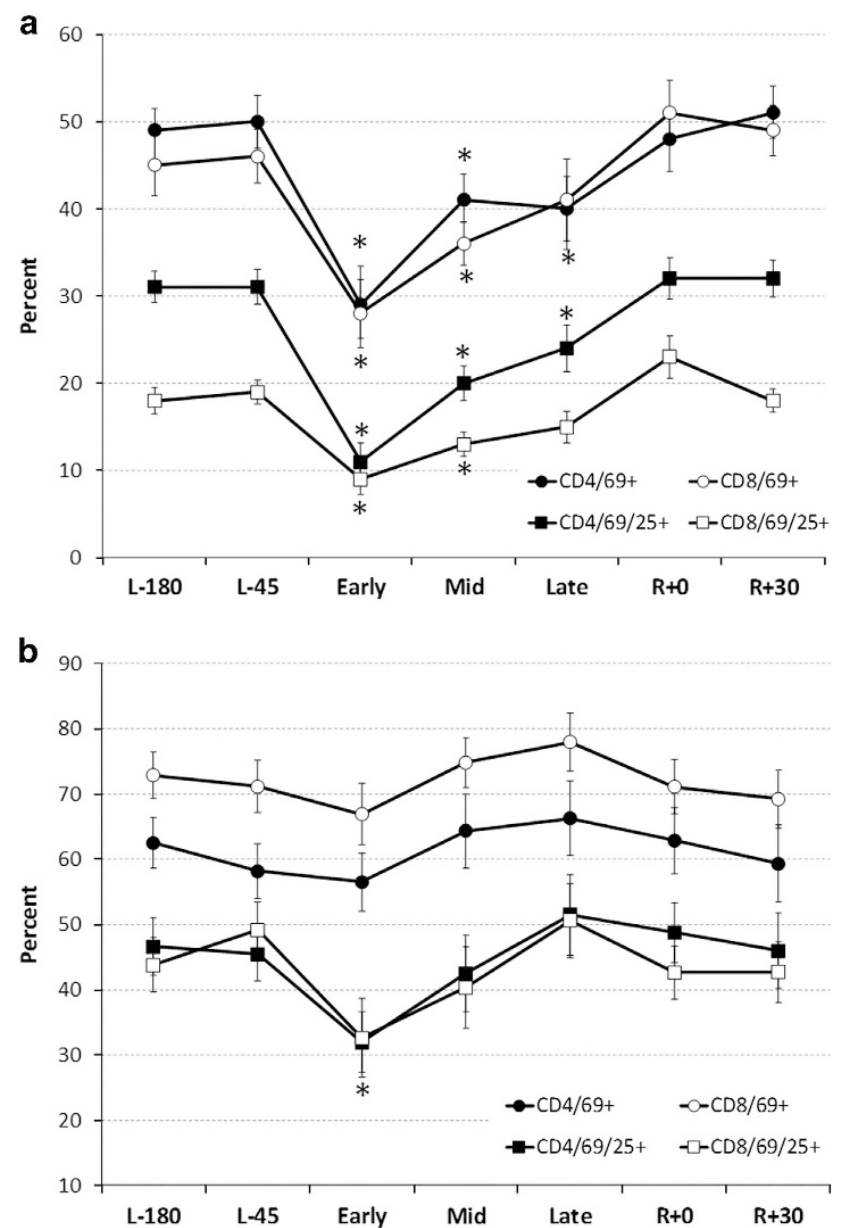

Figure 3. T-cell function (early blastogenesis) data: expression of either CD69 or CD69/CD25 following 24-h culture in the presence of (a) staphylococcal enterotoxin (a and $\mathbf{b}$ ); or (b) antibodies to CD3 and CD28. Data are presented as mean \pm standard error. Significance was evaluated via a Student's paired $t$-test by comparing all other data points to $L-180$ baseline data. Significant differences $(P \leqslant 0.05)$ are indicated $\left(^{*}\right)$. Sample size for all data is 23 ISS astronaut subjects. ISS, International Space Station.

we assessed a variety of adaptive immune parameters at three points (at $\sim 2$ weeks, between 2 and 4 months, and at 6 months) during long-duration orbital spaceflight. Given a lack of analytical equipment supporting immunology or hematology parameters on board ISS, the study was designed to collect samples on board ISS shortly before a vehicle undocking, so that ambient viable blood samples could be returned for terrestrial analysis. Blood collected in nutrient- and anticoagulant-containing ACD tubes was validated in the laboratory to maintain viability for the relevant cell populations and culture assays for up to $48-72 \mathrm{~h}$, which was the nominal delay until processing and analysis (data not shown). For each subject, in-flight data were compared with baseline data collected 180 days before launch.

Operationally the study was conducted without incident. Crews were instructed in phlebotomy prior to mission start, and most flight samples were collected as instructed. Samples were returned within the timeframes designated, and were either recovered at the Kennedy Space Center or Edwards Air Force Base if returned on the Shuttle, or in Star City, Russia, if returned on Soyuz. Cellular purification, culture setup and post-culture processing, as well as immunophenotype staining, were all performed on location. Stained cell products or culture 

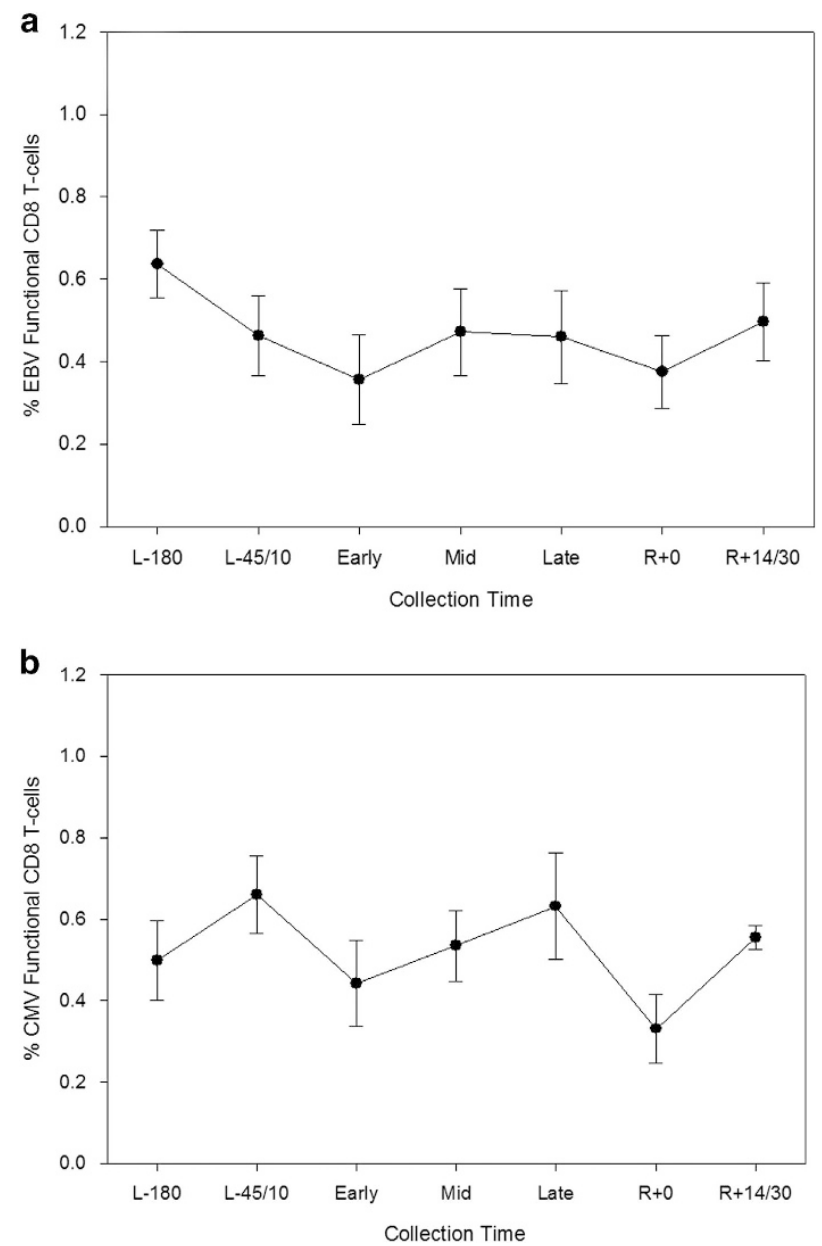

Figure 4. Quantification of virus-specific T-cell function. The frequency of $\mathrm{CD}^{+} 9^{+} / \mathrm{IFN} \gamma^{+}$positive (functional) $\mathrm{CD} 8^{+} \mathrm{T}$ cells following culture in the presence of $A^{*} 0201$-restricted viral peptides was evaluated by flow cytometry. The absolute and functional numbers of viral peptide-specific $T$ cells were used to derive a functional percentage for (a) EBV-specific and (b) CMV-specific CD8 ${ }^{+} \mathrm{T}$ cells during spaceflight. Significance was evaluated via a Student's paired $t$-test by comparing all other data points to L-180 baseline data. Significant differences $(P \leqslant 0.05)$ are indicated $(*)$. This assay is restricted to HLA-A2-positive subjects $(n=8)$. CMV, cytomegalovirus; EBV, Epstein-Barr virus.

supernatants were stabilized as appropriate (fixed or frozen) for transport to the Johnson Space Center for analysis.

The data revealed that with respect to the peripheral leukocyte distribution, the WBC count increases during spaceflight. A previously observed surge in the WBC count after landing was confirmed, but this finding has been purported to be solely a postflight effect mediated by stress-induced demargination of neutrophils. ${ }^{11}$ Terrestrial space analog studies have suggested that altered leukocyte distribution in astronauts may result from stress and not microgravity conditions. ${ }^{34}$ For ISS crews the WBC count was significantly elevated during missions at both the early and late time points, relative to the L-180 baseline data. No in-flight alterations were observed among the bulk lymphocyte, $T$ and T-memory subsets, with the exception of an increased NK-cell concentration at the late in-flight timepoint. Previous studies have actually reported decreased percentages of NK cells ${ }^{7,35}$ or decreases in NK-cell functional capabilities $7,8,35$ associated with spaceflight. Other studies indicate no decrement to NK function during flight. ${ }^{6}$ A recent investigation of Shuttle astronauts found no difference in NK concentration during flight, but a significant decrease following flight. ${ }^{23}$ Although the literature may vary, the common finding among the various terrestrial analogs and human flight investigations appears to be unaltered or decreased numbers of NK cells, and reduced (although sometimes targetselective) NK-cell function. Although NK-cell function was not evaluated for the current study, primarly due to sample volumes considerations, our finding of an actual increase in NK-cell levels late during ISS missions is discordant with some of these previous reports. Although the reason for the contrary NK finding is unknown, it may relate to the wide disparity between the experimental platforms, terrestrial analogs, short-duration postflight and in-flight, and even long-duration flight but on different vehicles. A follow up investigation of both NK-cell number and function on ISS astronauts, focusing on other uninvestigated innate immune parameters may be warranted.

'Fine' T-cell subsets were assessed using a variety of markers. An in-flight increase was observed for the 'cytotoxic' $\mathrm{CD} 8^{+}$subset $\left(\mathrm{CD} 28^{+} / \mathrm{CD} 244^{+}\right)$, whereas a decrease was observed for the central memory subset $\left(\mathrm{CD} 6 \mathrm{~L}^{+} / \mathrm{CD} 45 \mathrm{RA} \mathrm{A}^{-}\right)$. Several markers of senescence were assessed. $A$ decrease in senescent $C D 8^{+} T$ cells was observed during flight by using both the $\mathrm{CD} 244^{+} / \mathrm{CD} 28^{-}$phenotype and expression of CD57 as senescence markers. CD69 and HLA-DR were used to assess constitutively activated T cells. Although it trended upwards relative to preflight baseline data, the number of $\mathrm{CD} 9^{+} \mathrm{T}$ cells did not increase during flight for either the $\mathrm{CD} 4^{+}$or $\mathrm{CD}^{+}$subset. However, the number of $\mathrm{CD} 8^{+} / \mathrm{HLA}-\mathrm{DR}^{+} \mathrm{T}$ cells decreased during flight, reaching significance at the mid-mission timepoint. No alteration in the level of EBV- or CMV-specific T cells was observed during flight, although being HLA restricted, this assay was performed on only 10 crewmembers.

This leukocyte distribution pattern suggests that some in vivo immunological processes are occurring and persisting during long-duration spaceflight, including an elevated WBC count, largely because of an increased number of neutrophils and a shift within the $\mathrm{CD}^{+}{ }^{+}$-cell compartment toward a more active phenotype. It is possible that these alterations represent innate immunity compensating for diminished adaptive immune capacity. It is also possible that maturation shifts within $\mathrm{CD}^{+} \mathrm{T}$ cells may parallel persistent latent herpes virus reactivation.

Functional analyses were also performed as part of this flight investigation. CD69, preformed in the cytoplasm, is expressed about $1 \mathrm{~h}$ after activation, whereas CD25 requires new mRNA synthesis and is expressed closer to $24 \mathrm{~h}$ after activation. Therefore, following $24 \mathrm{~h}$ of mitogenic stimulation, the assessment of CD69 and CD25 constitutes a measurement of T-cell ability to progress through early activation events. Assessment of these two markers as a measure of T-cell activation potential as been previously established. $^{31}$ Two T-cell mitogens were used separately, a combination of SEA+SEB or soluble antibodies to both the TCR (CD3) and CD28. In the former, costimulation is mediated by antigen presenting cell (APC) binding, whereas in the latter costimulation is delivered by direct $\mathrm{CD} 28$ triggering. These mitogens by nature trigger different percentages of responding cells; enterotoxins a specific $V \beta$ T-cell subset, whereas soluble antibodies to CD3 theoretically may stimulate all available $T$ cells. However, as previously postulated, ${ }^{23}$ these mitogens may also be delivering differing strengths of signal to the nucleus. It is possible that enterotoxins may deliver a weaker 'physiological' signal (SEA +SEB) by triggering only at the cell:cell interface, whereas anti-CD3/ CD28 may deliver a more powerful signal via binding of all available ligands on the cell surface.

Similar to a previous assessment during short-duration spaceflight, ${ }^{23}$ during ISS missions disparate results were observed between the two mitogens. During flight, activation responses for both the CD4+ and $\mathrm{CD}^{+}$T-cell subsets following SEA+SEB stimulation were significantly reduced, a finding which, although it trended toward baseline, remained largely significant for the duration of the 6-month spaceflight (Figure 3a). Conversely, in assessment of total $\mathrm{CD} 69^{+}$, no reduction in T-cell function was 
a
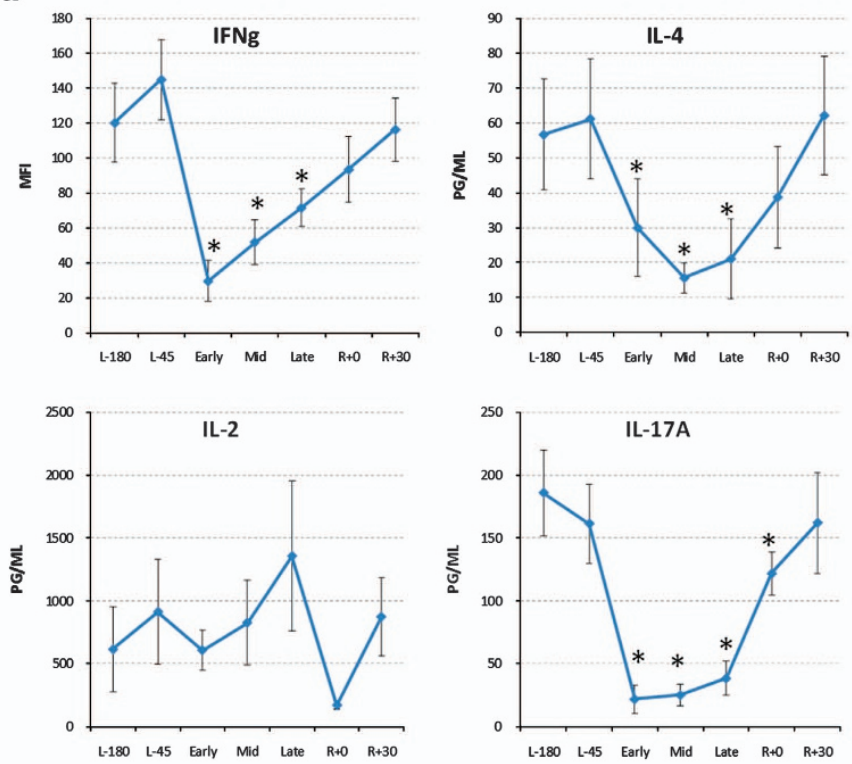

b
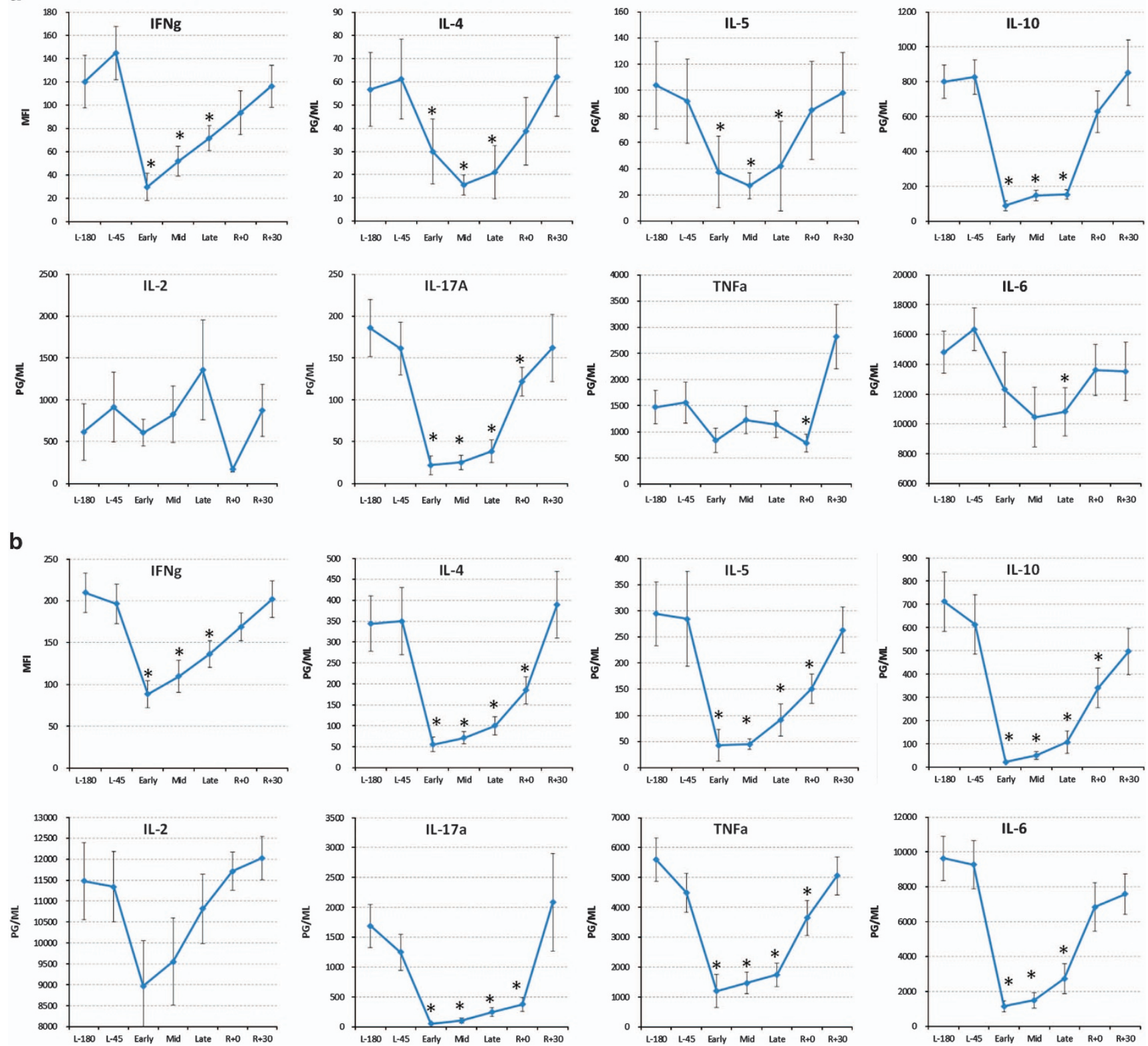

Figure 5. Mean secreted cytokine levels following mitogenic stimulation. For secreted cytokine production, the mitogen was (a) antibodies to both CD3 and CD28, (b) PMA+ionomycin or (c) LPS. Cytokine concentration data are expressed mean concentration in pg/ml \pm s.e.m. The lone exception is IFN $\gamma$, for which data is presented as mean fluorescence intensity (MFI), which corresponds to concentration. Significance was evaluated via a Student's paired $t$-test by comparing all other data points to L-180 baseline data. Significant differences $(P \leqslant 0.05)$ are indicated $(*)$. Sample size for all data is 23 ISS astronaut subjects. For IL-4 (a), late time point only, one outlier value removed prior to statistical analysis. ISS, International Space Station; LPS, lipopolysaccharide.

observed during spaceflight following CD3 and CD28 stimulation (Figure 3b). When $\mathrm{CD} 25^{+}$was assessed, however, a significant decrease was observed at the early in-flight timepoint only. The concept of an activation threshold shift has been established previously. ${ }^{36}$ We suggest the possibility that T cells from astronauts participating in long-duration spaceflight may, as was suggested previously based on similar short-duration findings, display an activation 'threshold shift' during spaceflight. ${ }^{23}$ Functional lymphocyte alterations observed during microgravity cell culture have been found to persist well after return to terrestrial unit gravity conditions. $^{21}$ We believe that our data can be explained as observation of an activation threshold shift, via the delivery of a 'physiological strength' signal by SEA+SEB, and a more potent activation signal by anti-CD3/CD28 antibodies. Terrestrial modeled microgravity mechanistic studies may be necessary to ascertain whether a threshold shift is associated with microgravity, which could explain many of the terrestrial analog (modeled microgravity) findings regarding a depression in T-cell activation associated with altered gravity fields. ${ }^{14,32}$ Alternative explanations are possible, in particular that the APC population, necessary only for the enterotoxin stimulation, may be more sensitive to the effects of spaceflight. However the LPS induced production of IL-8, a product of innate immune cells, was actually elevated during spaceflight. Although further studies of APCs would be necessary, this finding suggests APCs are viable and functional in our culture system.

It is interesting that the findings of immune system alterations in astronauts would be observed using blood samples collected 
C
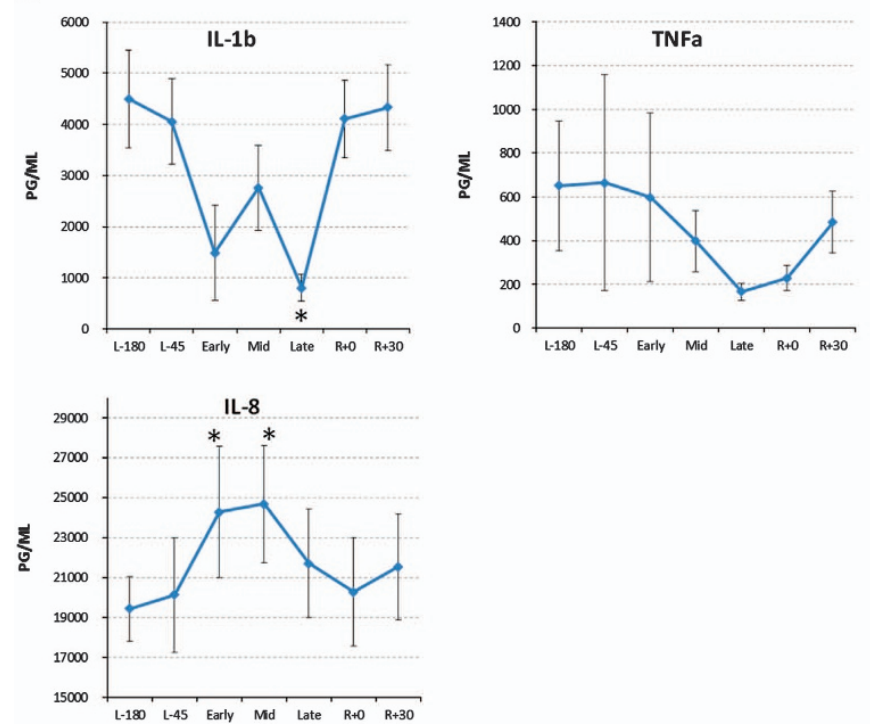

Figure 5. Continued.
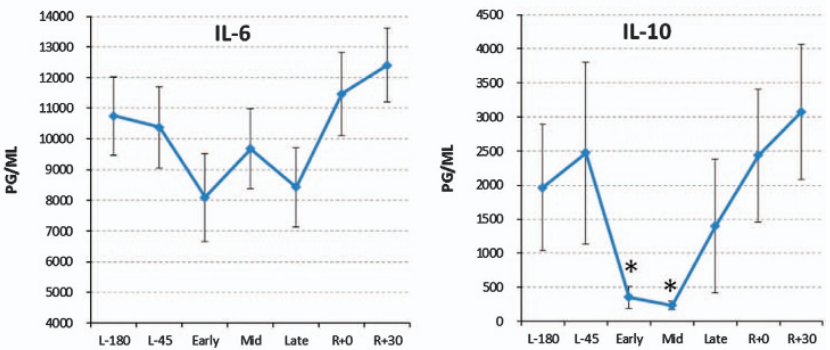

during flight, yet processed using $1 \mathrm{~g}$ terrestrial cell culture conditions. Alternative to a microgravity-related cause, it is also possible that other factors such as physiological stressors could at least partially explain the observations. Astronauts do work in an environment with multiple stressors, which may vary in duration in intensity. Assessments of urine and plasma cortisol have been assessed during flight, but reported alterations have varied considerably during studies, reviewed by Pierson et al. ${ }^{37}$ Generally, urine cortisol appears commonly elevated early during flight, but returns to baseline following adaptation. It appears that longer flight may manifest greater activation of the HPA axis than shorter flights. $^{18}$

Secreted cytokine production represents a more downstream measure of cellular function. For this flight investigation cultures were maintained for $48 \mathrm{~h}$, and supernatants were then assessed for cytokine concentrations. The mitogens used were as follows: anti- CD3/CD28 to stimulate T cells; PMA+ionomycin as a broader pharmacological stimulus (bypassing several gravi-sensitive signal transduction pathways); and LPS to stimulate innate immune cells. Following T-cell stimulation, production of IFN $\gamma$, IL-10, IL-5, and IL-17A were all significantly decreased at all three in-flight time points. Following stimulation by PMA-ionomycin, a mitogen which was thought would overcome depressions in in-flight cellular function, a remarkable pattern of suppression was observed. Concentrations of IFN $\gamma$, IL-4, IL-5, IL-10, IL-17A, TNFa, and IL- 6 were all significantly decreased at all three in-flight time points. Following stimulation with LPS, no significant decreases were observed during flight, but the concentration of IL-8 was actually increased at all three in-flight time points (Figure 5c).

Intracellular cytokine detection by flow cytometry, in positively identified cell subsets, has the capacity to measure the numbers of cells capable of being stimulated to produce cytokine, as opposed to bulk production levels. It is well understood terrestrially that it is typically only PMA+ionomycin stimulation that generates concentrations high enough so that, after secretion is blocked, cytokine levels will accumulate within the cell to detectable levels. For this study, the percentages of T-cell subsets capable of being stimulated to produce IL-2 and IFN $\gamma$ were determined. During flight, no significant alteration was observed in the percentage of $\mathrm{CD}^{+}{ }^{+} \mathrm{T}$ cells capable of being stimulated to produce IL-2, nor in the percentage of $\mathrm{CD}^{+} \mathrm{T}$ cells capable of being stimulated to produce IFNץ. We suggest that these findings indicate that the decreases in secreted cytokines during flight are therefore due to diminished bulk production capability, as opposed to the exit of cytokine-secreting $T$ cells from the peripheral circulation.

These summary functional changes indicate that crewmembers on board ISS do possess significant functional immune alterations that persist for the duration of a 6-month orbital spaceflight. These alterations may partly explain, from a mechanistic perspective, the root cause of the persistent reactivation of latent herpesviruses reported to occur during spaceflight. Although an attempt was made to investigate changes specific to various adaptive immune biases (Th1, Th2, Th17, and so on), no 'bias shifts' were observed. Instead, the functional depressions seem to be across the various aspects of adaptive T-cell immunity. Although this study did not investigate innate immunity in a comprehensive fashion, the lack of cytokine suppression following LPS stimulation may indicate that innate parameters are unaffected. In fact, the increase in IL-8, coupled with other reports of a mild 'pro-inflammatory' state persisting during ISS missions, ${ }^{38}$ may indicate compensatory increases in innate immune function. We also interpret that the increase in IL-8 production supports the acceptability of the sampling architecture, including delays in processing, used for this study.

These data indicate that immune system alterations, a phenomenon previously established to occur post flight and during short-duration spaceflight, in fact persists during longduration missions. In an applied longitudinal survey of astronauts, it is of course difficult to ascertain the specific causal factors. Potential causes include microgravity exposure, confinement, disrupted circadian rhythms or the physiological stress associated with spaceflight itself. Also, the study was conducted in a fashion perceived to be the best for science, but within operational constraints. For example, the time of blood sample collection could vary within a day due to other mission-associated impacts to the daily schedule. As immune parameters are sensitive to circadian issues, inability to collect all samples in the morning may be a confounding factor. However, in the end any flight study must operate within certain operational constraints. It may also be postulated that the simple act of collecting and storing samples in microgravity may introduce some confounding variable. Unfortunately this is impossible to control, and as discussed earlier the sample-return terrestrial analysis strategy is believed to in fact be more relevant than the alternative microgravity cell culture and 
analysis. Nevertheless we consider it unlikely that microgravity culture would alter the samples in any appreciable way. As with any in-vitro assay, interpretation to the in vivo situation carries certain caveats, but the viral reactivation astronaut data ${ }^{24-28}$ and the MIR-18 crew delayed-type hypersensitivity data ${ }^{30}$ would seem to support the current interpretation.

Exploration-class deep space missions will consist of elevated radiation exposure beyond the Van Allen belt, limited clinical care capability based on that of the projected Orion vehicle (plus any 'transit phase' module), and other exploration-specific variables (toxins, planetary exploration risks). We suggest that based on the data presented herein, persistent immune system alterations during these missions of exploration could increase specific clinical risks during exploration missions. At this point, as various aspects of immunity during spaceflight remain uninvestigated, further characterization of the in-flight phenomenon would be necessary prior to assessing specific health risks. The complete characterization would need to be interpreted in the context of terrestrial disease findings. It is possible that the immune changes in astronauts may be physiological indicators which may precede specific disease. If so, the development of immune-specific countermeasures, similar to those being developed for other physiological aspects of flight (bone loss, renal stone risk, and so on) would be necessary to ensure the health of astronauts.

\section{ACKNOWLEDGMENTS}

We thank the International Space Station crewmembers for participating in this study. We also acknowledge the support provided by the JSC Clinical Laboratory, the ISC Mission Integration Team, and the Kennedy Space Center Baseline Data Collection Facility during this study. We are particularly grateful for operational support provided by Mimi Shao at the Kennedy Space Center and Matt Roper at the Johnson Space Center. Also, we thank Dr Robert Ploutz-Snyder, Biostatistician at the Johnson Space Center for his suggestions regarding data analysis and interpretation. This work was supported by National Aeronautics and Space Administration.

\section{CONTRIBUTIONS}

BC: study operational support, flow cytometry assays, manuscript preparation. RPS: virus-specific immunity assays. SM: Virus reactivation assays. HQ: Study operational support, flow cytometry assays. DP: virus reactivation assays. CS: principal investigator.

\section{COMPETING INTERESTS}

DP is a NASA Virologist and CS and BC are NASA Immunologists. All remaining authors possess positions (contractor scientist) at, or are funded by, NASA. The remaining authors declare no conflict of interest.

\section{FUNDING}

This work was funded by the National Aeronautics and Space Administration Human Research Program's Human Health and Countermeasures Element.

\section{REFERENCES}

1 Chapes SK, Morrison DR, Guikema JA, Lewis ML, Spooner BS. Production and action of cytokines in space. Adv Space Res 1994; 14: 5-9.

2 Crucian BE, Stowe RP, Pierson DL, Sams CF. Immune system dysregulation following short- vs long-duration spaceflight. Aviat Space Environ Med 2008; 79: 835-843.

3 Sonnenfeld G, Miller ES. The role of cytokines in immune changes induced by spaceflight. J Leukoc Biol 1993; 54: 253-258.

4 Sonnenfeld G. Effect of space flight on cytokine production. Acta Astronaut 1994; 33: $143-147$.

5 Morukov VB, Rykova MP, Antropova EN, Berendeeva TA, Ponomarev SA, Larina IM Indicators of innate and adaptive immunity of cosmonauts after long-term space flight to international space station. Fiziol Cheloveka 2010; 36: 19-30.

6 Buravkova LB, Rykova MP, Grigorieva V, Antropova EN. Cell interactions in microgravity: cytotoxic effects of natural killer cells in vitro. J Gravit Physiol 2004; 11: P177-P180.
7 Konstantinova IV, Rykova M, Meshkov D, Peres C, Husson D, Schmitt DA. Natural killer cells after ALTAIR mission. Acta Astronaut 1995; 36: 713-718.

8 Meshkov D, Rykova M. The natural cytotoxicity in cosmonauts on board space stations. Acta Astronaut 1995; 36: 719-726.

9 Rykova M, Antropova IM, Larina IM, Morukov BV. Humoral and cellular immunity in comsonauts after the ISS missions. Acta Astronaut 2008; 63: 697-705.

10 Crucian BE, Cubbage ML, Sams CF. Altered cytokine production by specific human peripheral blood cell subsets immediately following space flight. J Interferon Cytokine Res 2000; 20: 547-556.

11 Stowe RP, Sams CF, Mehta SK, Kaur I, Jones ML, Feeback DL et al. Leukocyte subsets and neutrophil function after short-term spaceflight. J Leukoc Biol 1999; 65: 179-186.

12 Kaur I, Simons ER, Castro VA, Ott CM, Pierson DL. Changes in monocyte functions of astronauts. Brain Behav Immun 2005; 19: 547-554.

13 Kaur I, Simons ER, Castro VA, Mark Ott C, Pierson DL. Changes in neutrophil functions in astronauts. Brain Behav Immun 2004; 18: 443-450.

14 Boonyaratanakornkit JB, Cogoli A, Li CF, Schopper T, Pippia P, Galleri G et al. Key gravity-sensitive signaling pathways drive $T$ cell activation. FASEB J 2005; 19: 2020-2022.

15 Cogoli A. The effect of space flight on human cellular immunity. Environ Med 1993; 37: 107-116.

16 Schwarzenberg M, Pippia P, Meloni MA, Cossu G, Cogoli-Greuter M, Cogoli A. Signal transduction in $T$ lymphocytes--a comparison of the data from space, the free fall machine and the random positioning machine. Adv Space Res 1999; 24: 793-800.

17 Stowe RP, Sams CF, Pierson DL. Effects of mission duration on neuroimmune responses in astronauts. Aviat Space Environ Med 2003; 74: 1281-1284.

18 Stowe RP, Sams CF, Pierson DL. Adrenocortical and immune responses following short- and long-duration spaceflight. Aviat Space Environ Med 2011; 82: 627-634.

19 Grove DS, Pishak SA, Mastro AM. The effect of a 10-day space flight on the function, phenotype, and adhesion molecule expression of splenocytes and lymph node lymphocytes. Exp Cell Res 1995; 219: 102-109.

20 Nash PV, Konstantinova IV, Fuchs BB, Rakhmilevich AL, Lesnyak AT, Mastro AM. Effect of spaceflight on lymphocyte proliferation and interleukin-2 production. $J$ Appl Physiol 1992; 73: 186S-190S.

21 Pellis NR, Goodwin TJ, Risin D, Mclntyre BW, Pizzini RP, Cooper D et al. Changes in gravity inhibit lymphocyte locomotion through type I collagen. In Vitro Cell Dev Biol Anim 1997; 33: 398-405.

22 Taylor GR, Janney RP. In vivo testing confirms a blunting of the human cell-mediated immune mechanism during space flight. J Leukoc Biol 1992; 51: 129-132.

23 Crucian B, Stowe R, Mehta S, Uchakin P, Quiriarte H, Pierson D et al. Immune system dysregulation occurs during short duration spaceflight on board the space shuttle. J Clin Immunol 2012; 33: 456-465.

24 Payne DA, Mehta SK, Tyring SK, Stowe RP, Pierson DL. Incidence of Epstein-Barr virus in astronaut saliva during spaceflight. Aviat Space Environ Med 1999; 70: 1211-1213.

25 Mehta SK, Stowe RP, Feiveson AH, Tyring SK, Pierson DL. Reactivation and shedding of cytomegalovirus in astronauts during spaceflight. J Infect Dis 2000; 182: 1761-1764.

26 Mehta SK, Cohrs RJ, Forghani B, Zerbe G, Gilden DH, Pierson DL. Stress-induced subclinical reactivation of varicella zoster virus in astronauts. $J$ Med Virol 2004; 72: 174-179.

27 Mehta SK, Laudenslager ML, Stowe RP, Crucian BE, Sams CF, Pierson DL. Multiple latent viruses reactivate in astronauts during Space Shuttle missions. Brain Behav Immun 2014; 41: 210-217.

28 Pierson DL, Stowe RP, Phillips TM, Lugg DJ, Mehta SK. Epstein-Barr virus shedding by astronauts during space flight. Brain Behav Immun 2005; 19: 235-242.

29 Mehta SK, Crucian BE, Stowe RP, Simpson RJ, Ott CM, Sams CF et al. Reactivation of latent viruses is associated with increased plasma cytokines in astronauts. Cytokine 2013; 61: 205-209.

30 Gmunder FK, Konstantinova I, Cogoli A, Lesnyak A, Bogomolov W, Grachov AW. Cellular immunity in cosmonauts during long duration spaceflight on board the orbital MIR station. Aviat Space Environ Med 1994; 65: 419-423.

31 Shibuya TY, Wei WZ, Zormeier M, Ensley J, Sakr W, Mathog RH et al. Anti-CD3/ anti-CD28 bead stimulation overcomes CD3 unresponsiveness in patients with head and neck squamous cell carcinoma. Arch Otolaryngol Head Neck Surg 1998; 126: $473-479$.

32 Hashemi BB, Penkala JE, Vens C, Huls H, Cubbage M, Sams CF. T cell activation responses are differentially regulated during clinorotation and in spaceflight. Faseb J 1999; 13: 2071-2082.

33 Crucian BE, Stowe RP, Mehta SK, Yetman DL, Leal MJ, Quiriarte HD et al. Immune status, latent viral reactivation, and stress during long-duration head-down bed rest. Aviat Space Environ Med 2009; 80: A37-A44. 
34 Stowe RP, Yetman DL, Storm WF, Sams CF, Pierson DL. Neuroendocrine and immune responses to 16 -day bed rest with realistic launch and landing $G$ profiles. Aviat Space Environ Med 2008; 79: 117-122.

35 Rykova MP, Sonnenfeld G, Lesnyak AT, Taylor GR, Meshkov DO, Mandel AD et al. Effect of spaceflight on natural killer cell activity. J Appl Physiol 1985; 73 196S-200S.

36 Manz BN, Jackson BL, Petit RS, Dustin ML, Groves J. T-cell triggering thresholds are modulated by the number of antigen within individual T-cell receptor clusters. Proc Natl Acad Sci USA 2011; 108: 9089-9094.

37 Pierson D, Mehta S, Stowe R. Reactivation of latent herpes viruses in Astronauts. In: Ader R, Psychoneuroimmunology. Elsevier, Inc.: Atlanta, GA, 2007, pp 851-868.
38 Crucian BE, Zwart SR, Mehta S, Uchakin P, Quiriarte HD, Pierson D et al. Plasma cytokine concentrations indicate that in vivo hormonal regulation of immunity is altered during long-duration spaceflight. $J$ Interferon Cytokine Res 2014; 34: 778-786.

(c) $($ ) This work is licensed under a Creative Commons Attributioncc) NonCommercial-NoDerivatives 4.0 International License. The images or other third party material in this article are included in the article's Creative Commons license, unless indicated otherwise in the credit line; if the material is not included under the Creative Commons license, users will need to obtain permission from the license holder to reproduce the material. To view a copy of this license, visit http:// creativecommons.org/licenses/by-nc-nd/4.0/ 